\title{
KREATIFITAS PEMBELAJARAN : PERSPEKTIF GURU SEJARAH PROVINSI DKI JAKARTA
}

\author{
Abrar \\ Email : abrar@unj.ac.id \\ Jurusan Sejarah Universitas Negeri Jakarta
}

\begin{abstract}
The purpose of this study was to obtain empirical data on learning creativity in the perspective of history teachers in DKI province. This study is a cross-sectional survey study. Data was obtained through a semi-closed questionnaire. Data analysis and interpretation are carried out with the criteria of numbers $0-25 \%$ very weak (very less, 26-50\% weak (less), 51-75\% sufficient (low) and $76-100 \%$ strong (high).The results of the study are four indicators in the low category, namely interaction with peers, sharing experiences, a mental block of creative thinking and practicing creativity. Four indicators in the high category are knowledgeable, a collector of ideas for teaching, experimenting and self-reflection, and creativity is a daily goal.
\end{abstract}

Keywords: Learning Creativity, History Teacher, DKI Province, Jakarta

\section{Pendahuluan}

Telah ada berbagai penelitian mengenai kreativitas pembelajaran antara lain penelitian Petkovska yang bertujuan untuk melihat hasil pembelajaran bahasa Inggris yang dilakukan dengan menerapkan empat metode mengajar kreatif (Petkovska, 2015). Penelitian dilakukan terhadap 20 orang mahasiswa yang heterogen dari segi asal dan kewarganegaraannya. Penelitian mengenai praktek metode pembelajaran yang mengembangkan kreativitas kepada mahasiswa (Daly, Mosyjowski, \& Seifert, 2014). Penelitian studi kasus itu berfokus pada tujuan pembelajaran, metode pembelajaran, dan penilaian yang terkait keterampilan kognitif.

Penelitian yang mengangkat masalah persepsi guru mengenai apa yang dimaksud dengan konsep guru kreatif dan apa pula mengenai siswa kreatif (Morais \& Azevedo, 2011). Penelitian menggunakan metode survey skala Likert ini dilakukan terhadap 576 guru kesenian, ilmu pengetahuan alam dan humaniora. Guru-guru tersebut berasal dari sekolah menengah pertama dan sekolah menengah atas. Penelitian lainnya mengenai hubungan iklim organisasi sekolah terhadap kreativitas guru (Terry, 2018). Metode yang digunakan dalam penelitian ini adalah metode survey dengan menggunakan skala Likert. Hasil penelitian menunjukkan terdapat hubungan positif antara iklim organisasi dengan kreativitas guru. Penelitian dilakukan terhadap 84 orang responden dari 9 SMA di Manado.

254 | Seminar Nasional Sejarah ke 4 Jurusan Pendidikan Sejarah Universitas Negeri Padang 
Kreativitas adalah bagaimana menciptakan ide-ide baru yang berguna dimana ide-ide baru itu terkait dengan inovasi (the SCoTENS Committee and Secretariat, 2012). Sejalan dengan itu, National Advisory Committe on Creative and Cultural Education mengungkapkan bahwa kreativitas itu dilakukan untuk menghasilkan sesuatu yang orisinal ("National Advisory Committee on Creative and Cultural Education All Our Futures: Creativity, Culture and Education," 1999). Pope berpendapat bahwa kreativitas merupakan penerapan pengetahuan dan keterampilan dengan metode baru dalam mencapai suatu tujuan (Pope, 2005). Sedangkan Adair menyatakan bahwa kreativitas adalah kecakapan melakukan daya cipta yang membuka peluang munculnya sesuatu yang tidak bermanfaat menjadi sesuatu yang bernilai, apik dan elok (Adair, 2007). Hal itu menunjukkan dalam kreativitas dituntut kemampuan seseorang untuk keluar dari kebiasaan yang ada dan melakukan sesuatu yang baru agar tercapai tujuan yang diharapkan. Dengan demikian kreativitas lebih tertuju bagaimana seseorang terpusat perhatiannya pada cara berpikir untuk mencapai sesuatu yang berbeda. Cara berpikir yang berbeda dengan kebiasaan umum tersebut dinamakan dengan kecerdasan kreatif (Rowe, 2005).

Itu sebabnya guru kreatif adalah orang yang sadar dan menghargai kreativitas yang ada dalam diri mereka dan berusaha untuk mengenalkannya pada orang lain (Wilson \& Cremin, 2017). Guru kreatif (Morais \& Azevedo, 2011) adalah guru yang mau menanggung resiko dan pada situasi yang tidak terduga ketika melakukan kegiatan kreatif. Untuk menjadi guru kreatif ada tiga hal yang dapat dilakukan yaitu; (1) konsentrasikan diri pada perencanaan pembelajaran, (2) terbuka terhadap perubahan, dan (3) siap melakukan kerjasama.

Mengikut pendapat Constantini deskreativitas pembelajaran dapat dikembangkan dengan memperhatikan 8 kriteria seorang guru kreatifyaitu: (1) Guru mesti berpengetahuan luas, (2) Terhubung dengan teman sejawat, (3) Menjadi seorang kolektor ide mengajar, (4) Berbagi pengalaman pembelajaran, (5) Hilangkan mental blok berpikir kreatif, (6) melatih kreativitas, (7) Melakukan eksperimen dan refleksi pembelajaran, dan (8) Menjadikan kreativitas tujuan harian (Constantinides, 2015).

Abduh Zen menyebutkan bahwa guru meskipun telah memperoleh predikat sebagai pendidik umumnya masih konvensional dalam proses pembelajaran, menjemukan dan tidak imajinatif (Abduh Zen, 2018). Artinya guru, termasuk guru sejarah belum menunjukkan kreativitasnya dalam pembelajaran. Hal yang demikian itu tidak saja didapatkan dari temuan berbagai penelitian yang mengungkapkan pembelajaran sejarah membosankan, tetapi juga 
berdasarkan pengalaman bertemu dengan peserta didik. Bahkan guru-guru sejarahpun mengungkapkan bahwa pembelajaran sejarah belum menarik bagi peserta didik karena kurangnya kreativitas pembelajaran. Oleh karena itu maka tujuan dari penelitian ini untuk mendapatkan data empiric perspektif guru sejarah mengenai kreativitas pembelajaran.

\section{Metode}

Metode yang digunakan dalam penelitian ini adalah metode survey cross-sectional. Survei cross-sectional merupakan bentuk kategori survey deskriptif penelitian yang berupaya menjelaskan kondisi, sikap, keyakinan, pendapat atau opini, dan praktik yang terjadi dikalangan responden (Creswell, 2015; Morissan, 2016). Populasi target adalah seluruh guru sejarah SMA/SMK Negeri dan Swasta tempat dilaksanakannya PKM dan PPL serta guru-guru sejarah di Jakarta yang sedang mengikuti PPG dalam Jabatan. Oleh karena populasi target tidak mencapai 100 orang maka seluruh populasi target menjadi sampel dalam penelitian ini yang jumlahnya 79 orang.

Teknik pengumpulan data dalam penelitian ini dilakukan dengan menggunakan instrument berupa angket. Teknik analisis data yang digunakan dalam penelitian ini adalah deskriptif kuantitatif. Hasil dari perhitungan statistic tersebut selanjutnya diinterpretasi dengan menggunakan kriteria sebagai berikut (Riduwan, 2002):

Angka $0-25 \%=$ Sangat Lemah (Sangat Kurang)

Angka $26-50 \%=$ Lemah (Kurang)

Angka $51-75 \%$ = Cukup (Rendah)

Angka $76-100 \%=$ Kuat (Tinggi)

\section{Hasil Penelitian}

Penelitian yang dilaksanakan terhadap guru-guru sejarah yang sekolahnya dijadikan tempat pelaksanaan Praktik Keterampilan Mengajar (PKM), Program Praktik Lapangan (PPL) dan guru-guru sejarah yang ikut Program Profesi Guru Dalam Jabatan diperoleh hasil data penelitian mengenai kreativitas pembelajaran sebagaimana terlihat dari grafik 1. 


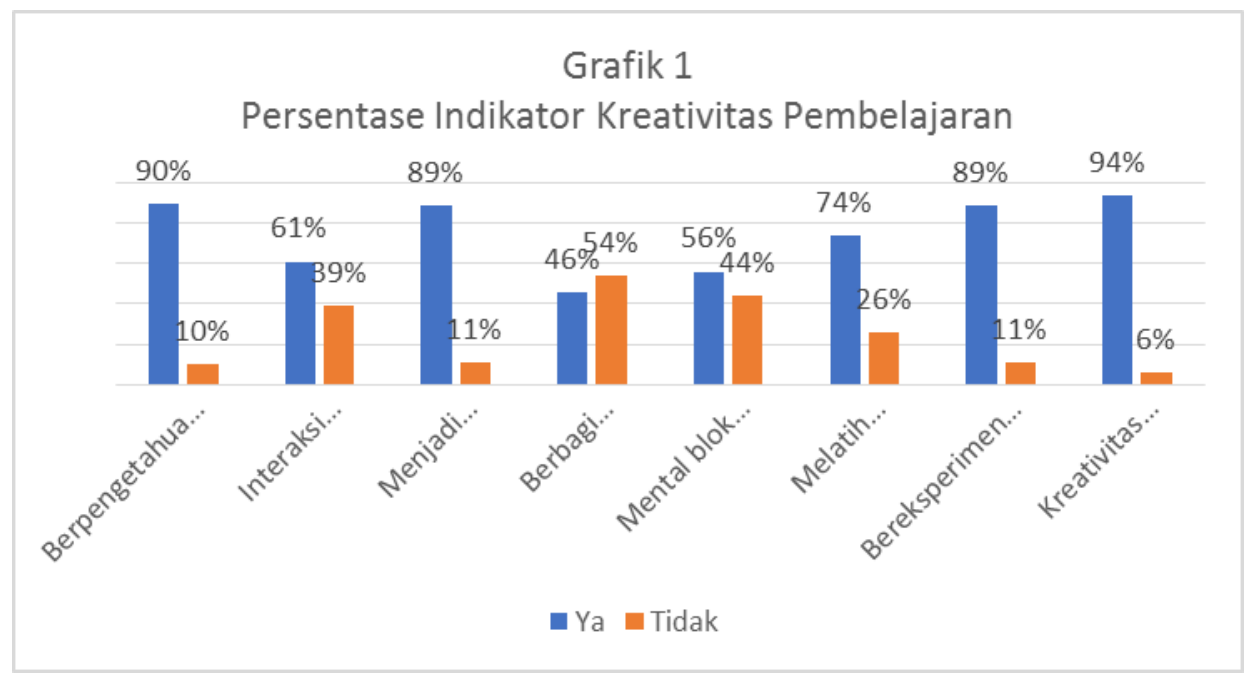

Guru yang diteliti secara umum guru yang usia produktif. Guru sejarah yang mendekati usia pensiun (di atas 55 tahun) jumlahnya 16\%. Sementara sisanya guru-guru usia sangat produktif mencapai $84 \%$. Bahkan yang usia sangat produktifitas itu ada yang usianya dibawah 26 tahun yang jumlahnya 3\%. Dari komposisi jenis kelamin guru yang diteliti sebanyak 59\% berjenis kelamin perempuan dan $41 \%$ berjenis kelamin laki-laki.

Pendidikan guru-guru yang diteliti secara umum Strata 1 (S1) program studi Ilmu Pengetahuan Sosial maupun Pendidikan Sejarah yang jumlahnya mencapai 91\%. Sedangkan pada jenjang S2 itu justru yang bukan berlatar belakang Ilmu Pengetahuan Sosial ataupun Pendidikan Sejarah jumlahnya lebih banyak dibandingkan yang berlatar belakang Ilmu Pengetahuan Sosial ataupun Pendidikan Sejarah yakni 57\% berbanding 43\%. Mereka ada yang berasal dari prodi Penelitian dan Evaluasi Pendidikan, Manajemen Pendidikan, Sumber Daya Manusia, Teknologi Pendidikan dan Administrasi Pendidikan.

Data kreativitas pembelajaran yang terdiri dari delapan indicator sebagaimana grafik 1 di atas, gambaran yang didapatkan sebagai berikut ini. Ada sebanyak $86 \%$ guru yang berpengetahuan luas. Hanya 14\% yang tidak berpengetahuan luas. Yang tidak berpengetahuan luas umumnya beralasan karena kurang membaca dan sibuk mengajar. Meskipun begitu ada juga yang beralasan bukan berlatar belakang Pendidikan Sejarah.

Pengetahuan luas guru-guru tersebut dikarenakan mereka 100\% membaca buku-buku lain selain buku sejarah. Buku-buku lain selain buku sejarah yang banyak dibaca guru adalah novel $29 \%$, hobi $25 \%$, sastra $24 \%$, olahraga $14 \%$, dan komputer $6 \%$. Sisanya sekitar $2 \%$ membaca 
buku antara lain buku agama, psikologi, pengetahuan modern, militer, biografi, motivasi dan masak.

Berkenaan dengan keanggotaan di organisasi MGMP Sejarah maupun Asosiasi Guru Sejarah Indonesia (AGSI) tidak semua guru menjadi anggota. Ada 94\% yang menjadi anggota MGMP Sejarah, sementara yang bukan anggota MGMP Sejarah ada 6\%. Alasan tidak menjadi anggota MGMP Sejarah adalah bukan berlatar belakang Pendidikan Sejarah dan baru mengajar sejarah. Pada organisasi AGSI yang menjadi anggota 34\%, sedangkan yang tidak menjadi anggota $66 \%$. Tidak menjadi anggota AGSI mereka umumnya beralasan tidak mengetahui organisasi tersebut keberadaannya. Sedangkan keaktifan dalam organisasi MGMP Sejarah dan Asosiasi Guru Sejarah Indonesia seperti hanya ada 14\% guru yang tidak aktif di MGMP Sejarah. Guru-guru yang tidak aktif pada kegiatan MGMP mempunyai alasan bahwa mereka bukan anggota MGMP, bukan berasal dari Pendidikan Sejarah, keterbatasan waktu karena jam mengajar yang banyak, tidak pernah mendapat undangan, dan lebih mengutamakan guru senior. Pada sisi yang lain ketidak aktifan pada organisasi AGSI mencapai 78\%. Ketidak aktifan pada organisasi AGSI disebabkan bukan menjadi anggota AGSI dan kesibukan mengajar yang tidak bisa ditinggalkan.

Bentuk keaktifan guru-guru sejarah baik dalam kegiatan MGMP Sejarah maupun AGSI lebih banyak sebagai peserta dalam seminar yang mencapai 61\%. Sedikit guru-guru yang dalam kegiatannya menjadi narasumber yaitu $8 \%$. Kegiatan lainnya seperti membuat soal dan bedah SKL (Standar Kompetensi Lulusan) ada 11\% dan peserta lokakarya 15\%. Sedangkan yang tidak aktif ada $5 \%$.

Guru-guru aktif yang dalam kegiatan seminar dan lokakarya yang dilaksanakan oleh Kementerian Pendidikan dan Kebudayaan mencapai 71\%, sedangkan yang tidak aktif $29 \%$. Sementara keaktifan guru-guru dalam kegiatan seminar dan lokakarya yang diselenggarakan oleh Universitas atau instansi lain sebanyak 65\% mengikuti seminar dan lakakarya yang diselenggarakan Universitas Negeri Jakarta. Data juga menunjukkan cukup banyak juga guruguru yang tidak pernah mengikuti seminar dan lokakarya di Universitas atau instansi lainnya yang jumlahnya ada 23\%. Sisanya sebanayak $12 \%$ guru-guru tersebut mengikuti seminar dan lokakarya yang diselenggarakan Komnas Perempuan, Universitas Indonesia, Universitas Sanata Dharma, dan Universitas Negeri Semarang yaitu sebanyak 5\%. 
Sehubungan dengan pertanyaan menemukan dan mengumpulkan ide-ide mengenai aspek pedagogic pembelajaran sejarah ada sebanyak $87 \%$ guru melakukannya. Sedangkan $13 \%$ tidak menemukan dan mengumpulkan ide-ide mengenai aspek pedagogic pembelajaran sejarah. Bagi yang tidak menemukan dan mengumpulkan tersebut alasan yang dikemukakannya adalah sibuk mengajar, sudah ada dalam kurikulum 2013 dan sudah ada dalam buku pembelajaran.

Sebanyak $91 \%$ guru-guru tersebut mencoba melaksanakan ide-ide pembelajaran yang mereka temukan. Hanya 9\% yang tidak melaksanakan ide-ide pembelajaran tersebut. Bagi yang mencoba melaksanakan ide-ide pembelajaran sejarah, model dan metode yang mereka anggap baru sebanyak 32\% memilih Problem Based Learning, 37\% Discovery Learning, 26\% Project Based Learning, dan 14\% Inquiry Based Learning.

Selain keempat model atau metode di atas, guru-guru sejarah mengemukakan bahwa terdapat ide-ide lain yang merupakan ide baru dalam pembelajaran sejarah. Guru sejarah berpandangan Jigsaw sebagai model dan metode yang baru dalam pembelajaran sejarah. Ada $10 \%$ yang berpandangan demikian, ada juga $10 \%$ yang berpandangan Cooperative Learning sebagai model dan metode pembelajaran sejarah yang baru. Ada 9\% yang menjadikan Role Playing sebagai model dan metode baru dalam pembelajaran sejarah. Ada 4\% Study Tour, 3\% Group Investigation, 3\% Contextual Learning, 3\% Snowball, dan 3\% Cooperative Script. Model dan metode lain yang mencapai 26\% meliputi Galery Walk, Talking Stick, Card Sort, Numbered Head Together, Puzzle, Film Sejarah, Mind Mapping, Metode Debat, Values Exploration, Windows Shopping dan seterusnya. Masing-masing model dan metode tersebut berkisar antara 1$2 \%$ jumlahnya. Namun demikian cukup banyak juga yang menjawab tidak tahu yakni sebanyak $29 \%$.

Data tentang berbagi pengalaman terdapat $92 \%$ yang berbagi pengalaman melalui pertemuan organisasi, hanya $8 \%$ yang tidak melakukan. Berbagi melalui blog pribadi terdapat $22 \%$ yang melakukan dan $78 \%$ tidak melakukan. Sedangkan melalui jurnal sejarah atau pendidikan sejarah jumlahnya $25 \%$ yang melaksanakan dan $75 \%$ yang tidak melaksanakan. Bagi yang tidak menulis pada jurnal umumnya disebabkan tidak mempunyai kemampuan menulis artikel. Selain itu juga ada disebabkan terlalu sibuk dengan jam mengajar dan keterbatasan literatur.

Penggunaan media social selain blog pribadi untuk berbagi pengalaman datanya menunjukkan sebanyak $61 \%$ berbagi pengalaman melalui WhatsApp. Melalui Instagram 18\%, 
Facebook 3\%, Line 3\%, dan Telegram 1\%. Namun ada juga yang tidak pernah berbagi pengalaman di media sosial yang jumlahnya mencapai $13 \%$.

Berkenaan dengan mempunyai kemampuan yang berbeda dengan teman lain dan memiliki potensi untuk kreatif guru-guru memberikan jawaban sebanyak $51 \%$ mempunyai kemampuan berbeda dan 49\% tidak mempunyai kemampuan berbeda. Sedangkan dari segi potensi diri sebanyak $62 \%$ berpotensi untuk kreatif dan $38 \%$ tidak berpotensi kreatif.

Melatih otak dengan menikmati kegiatan mengisi teka teki silang, bermain sudoku dan sejenisnya dilakukan oleh $63 \%$ guru dan $37 \%$ yang tidak melakukannya. Pada sisi yang lain guru-guru sejarah secara rutin berlatih mengenai keterampilan pedagogik yang jumlahnya mencapai $84 \%$ dan ada $16 \%$ yang tidak berlatih secara rutin. Mereka yang tidak melakukan latihan secara rutin disebabkan terbatasnya waktu yang tersediakarenabebanmengajar dan beban administratif. Selain itu ada juga yang disebabkan tidak adanya teman berlatih.

Guru-guru sejarah tersebut sebanyak $82 \%$ melakukan eksperimen mengenai pedagogik dan $18 \%$ tidak melakukan eksperimen. Guru-guru yang tidak melakukan eksperimen umumnya disebabkan beban mengajar yang terlalu banyak, beban administrasi dan tidak adanya teman sejawat yang membimbing. Melakukan refleksi mengenai pelaksanaan pembelajaran pada setiap akhir semester dilakukan oleh $96 \%$ guru sejarah. Hanya 4\% yang tidak melakukan evaluasi dengan alasan sibuk.

Memecahkan masalah di kantor terkait pembelajaran termasuk membantu individu peserta didik yang tidak mengalami kemajuan dalam pembelajaran dilakukan oleh guru sejarah yang jumlahnya mencapai $97 \%$. Sebanyak 3\% saja yang tidak melakukan hal tersebut. Ada sebanyak 96\% guru sejarah yang menciptakan pembelajaran yang memotivasi, produktif dan menarik bagi peserta didik. Sedangkan yang tidak melakukannya terdapat $4 \%$ guru. Selanjutnya berkaitan dengan memiliki kesabaran, dedikasi dan hasrat untuk lebih unggul dalam pembelajaran terdapat $97 \%$ guru yang melaksanakan. Dengan demikian hanya ada $3 \%$ yang tidak melakukan hal tersebut.

Data yang terkait dengan memiliki kemampuan dan hobi dalam bidang seni seperti mendengarkan lagu, bermain musik, bermain drama, menyanyikan lagu dan lain-lain sebanyak 46\% guru sejarah memiliki kemampuan dan hobi mendengarkan lagu, menyanyikan lagu ada $31 \%$, bermain drama $8 \%$, bermain music $7 \%$, menonton film $4 \%$, traveling $2 \%$ dan membaca puisi dan menikmati lukisan masing-masing $1 \%$. 
Kemampuan dan hobi yang dimiliki guru-guru sejarah seperti terungkap di atas sebanyak 85\% digunakan oleh guru-guru sejarah dalam pembelajaran sejarah. Sedangkan 15\% tidak menggunakannya dengan alasan keterbatasan waktu, kurang relevan dan dapat mengganggu proses pembelajaran.

\section{Pembahasan}

Guru sejarah yang diteliti menunjukkan rendah perspektifnya mengenai kreativitas pembelajaran. Rata-rata indicator kreativitas pembelajaran hanya mencapai $75 \%$. Temuan tersebut tidak berbeda jauh dengan temuan Morais dan Azevedo (2011) yang mengemukakan bahwa persepsi kreativitas guru-guru Portugal hanya 78\%. Padahal temuan Richard (2013) menyatakan bahwa kreativitas pembelajaran yang dilakukan guru di kelas dapat meningkatkan kreativitas peserta didik. Abedini dan Broujeni (2016) juga menyebutkan bahwa kreativitas pembelajaran seorang guru mempunyai peran penting dalam mencapai tujuan pendidikan, termasuk pembelajaran bermakna, kritis dan mampu memecahkan masalah. Sementara Ayob, Hussain, dan Majid (2013) menyampaikan guru yang mempunyai kreativitas pembelajaran dapat menanamkan keterampilan peserta didik dalam menghadapi globalisasi. Dengan rendahnya kreativitas pembelajaran guru-guru sejarah yang diteliti tentunya peserta didik akan rendah juga hasil pembelajarannya. Sesuatu yang sesungguhnya tidak diharapkan dalam dunia pendidikan.

Dari delapan indicator kreativitas ada satu indikator yang angka rata-ratanya berada dibawah 50\%. Angka itu memperlihatkan lemahnya guru-guru sejarah DKI Jakarta dalam hal berbagi pengalaman. Sementara ada tiga indikator yang menunjukkan kategori rendah atau cukup yaitu mental blok berpikir kreatif, berhubungan dengan teman sejawat, dan melatih kreativitas.

Pada sisi yang lain indicator kreativitas menjadi tujuan harian guru sejarah angkanya mencapai 94\%. Nampaknya itu disebabkan guru-guru yang di survey secara usia didominasi oleh guru-guru yang sangat produktif. Guru-guru sangat produktif itu secara usia berada dibawah 45 tahun yang jumlahnya mencapai 57\%.

Guru sejarah dari segi pengetahuan punya perspektif yang tinggi juga. Sebabdilihatdari rata-rata membacanyabaikbukusejarah dan non sejarahmencapaiangka 90\%. Hanyaada 10\% yang sangat kurang dalam membaca baik buku sejarah maupun buku non sejarah. Oleh karena itu menggunakan hobi dalam pembelajaran sejarah juga tinggi yang mencapai $85 \%$. Kondisi 
sangat kurang dalam membaca baik buku sejarah maupun non sejarah diduga terjadi dikalangan guru-guru yang berlatar bukan pendidikan sejarah ataupun guru-guru sejarah yang baru mengajar mata pelajaran sejarah.

Menjadikolektor ide-ide mengajar rata-ratanyamencapai 89\%. Artinya guru-guru sejarah yang di surveitinggiperspektifnyadalamhalmengumpulkanberbagai ide-ide mengajar. Merekaberpandanganbahwamodel ataumetode yang terdapatdalamkurikulum 2013 merupakan model ataumetodebarudalampembelajaransejarah. Namundemikianada model yang cukupmenarik yang munculdikalangan guru sejarahtersebutselain model ataumetode yang terdapatdalamkurikulum 2013. Ada model ataumetode yang jarang muncul dalam pembelajaran sejarah tetapi menarik untuk dibagikan dikalangan guru-guru sejarah yaitu model atau metode card sort, gallery walk, values exploration, dan windows shopping.

Bereksperimen dan melakukan refleksi diri dikalangan guru-guru sejarah perspektifnya rata-rata mencapai 89\%. Dengan demikian tinggi pandangan guru sejarah mengenai eksperimen dan evaluasi diri. Suatu hal yang memang dibutuhkan guru jika mereka ingin menjadi guru kreatif. Adalah hal yang mustahil jika sesorang guru tidak pernah bereksperimen ataupun mengevaluasi dirinya dapat tumbuh dan berkembang menjadi guru yang kreatif. Kesadaran melakukan eksperimen dan evaluasi diri yang semakin tinggi memungkinkan guru untuk dapat berpikir inovatif, memikirkan sesuatu yang baru yang berbeda dengan apa yang telah mereka lakukan selama ini.

Melatih kreativitas dikalangan guru sejarah masih rendah yang hanya berkisar 74\%, belum mencapai kategori tinggi. Padahal latihan melakukan sesuatu menjadi penting. Semakin sering seseorang melakukan latihan tertentu maka akan semakin mahir orang tersebut. Artinya tidak mungkin seorang guru sejarah akan tumbuh dan berkembang menjadi guru kreatif jika latihan untuk menjadi seorang yang kreatif masih rendah. Jika dilihat dari alasan yang $26 \%$ tidak melakukan latihan, alasannya merupakan alasan yang klasik yaitu kesibukan mengajar dan tidak ada yang membimbing. Sesuatu yang sebenarnya bisa diatasi asal guru yang bersangkutan mempunyai kemauan untuk itu.

Guru-guru sejarah nampaknya mempunyai problem yang serius berhubungan dengan teman sejawat. Meskipun mereka aktif sebagai peserta seminar, lokakarya atau sebagai pemateri pada kegiatan yang dilaksanakan MGMP Sejarah, Kementerian Pendidikan dan Kebudayaan, dan universitas tetapi keaktifan tersebut tidak ada yang mencapai angka di atas $75 \%$. Bahkan 
rata-rata persentase keaktifan itu hanya $61 \%$ dari berbagai bentuk kegiatan yang dilaksanakan baik oleh MGMP Sejarah, Asosiasi Guru Sejarah Indonesia, Kementerian Pendidikan dan Kebudayaan, dan Universitas. Hal itu menunjukkan partisipasi keaktifan guru-guru sejarah masih rendah. Padahal hadir dalam berbagai bentuk kegiatan yang diselenggarakan organisasi atau instansi tersebut semakin memudahkan mereka untuk punya hubungan dengan teman sejawat sebab bisa bertemu secara langsung dalam berbagai kegiatan yang ada.

Rendahnya keaktifan berhubungan dengan teman sejawat itu sejalan dengan lemahnya berbagi pengalaman dikalangan guru-guru sejarah. Sebab berbagi pengalaman persentasenya hanya mencapai 46\%. Berbagi pengalaman yang sangat rendah terjadi melalui blog pribadi dan menulis artikel di jurnal sejarah atau pendidikan sejarah. Lebih dari 75\% tidak pernah berbagi pengalaman di kedua area public tersebut. Kedua area public tersebut sebenarnya area yang membutuhkan tingkat percaya diri yang cukup tinggi untuk berbagi pengalaman dengan menampilkan tulisan-tulisan yang tentunya dapat dipertanggung jawabkan secara ilmiah. Guru sejarah masih cenderung berbagi pengalamannya dalam area "privat". Sebab ada 61\% yang berbagi pengalaman melalui WhattsApp, meskipun kecenderungan itu termasuk rendah.

\section{Simpulan}

Kreativitas pembelajaran dalam perspektif guru-guru sejarah yang diteliti menunjukkan hasil yang rendah. Capaian yang ditemukan tersebut dilihat dari rata-rata persentase yang memilih opsi jawabanya terhadap indikator yang terdiri dari; berpengetahuan luas, interaksi dengan teman sejawat, menjadi kolektor ide-ide mengajar, berbagi pengalaman, mental blok berpikir kreatif, melatih kreativitas, bereksperimen dan merefleksi diri dan kreativitas menjadi tujuan harian. Dari 8 indikator yang ada, sebanyak 4 indikator angkanya berkisar antara 46\%74\%. Empat indicator lainnya berkisar antara 89\%-94\%. Dengan demikian 4 indikator pada kategori rendah dan 4 indikator pada kategori tinggi. Empat indikator pada kategori rendah tersebut meliputi hubungan dengan teman sejawat, berbagi pengalaman, mental blok berpikir kreatif dan melatih kreativitas. Sedangkan empat indikator yang masuk kategori tinggi mencakup berpengetahuan luas, menjadi kolektor ide-ide mengajar, bereksperimen dan merefleksi diri, dan kreativitas menjadi tujuan harian. Rata-rata keseluruhan indicator hanya mencapai $75 \%$. 
Kondisi yang demikian itu nampaknya lebih karena guru-guru tidak punya waktu yang cukup untuk melakukan pengembangan diri. Mereka waktunya banyak tersita dengan kegiatan mengajar dan kegiatan administratif. Padahal berhubungan dengan teman sejawat dan berbagi pengalaman membutuhkan waktu untuk dapat beraktivitas di bidang tersebut. Sebab menulis di blog dan jurnal ilmiah membutuhkan waktu dan pikiran untuk dapat menghasilkan tulisan yang dapat dipertanggung jawabkan dan kredibel.

Guru sejarah yang diteliti menempatkan secara berturut-turut model atau metode pembelajaran Problem Based Learning, Discovery Learning, Project Based Learning, dan Inquiry Based Learning sebagai model atau metode baru dalam pembelajaran sejarah. Guru sejarah yang diteliti menjadikan model atau metode yang terdapat dalam kurikulum 2013 sebagai model atau metode baru dalam pembelajaran sejarah. Model atau metode pembelajaran sejarah selain yang ditetapkan dalam kurikulum 2013 yang merupakan model atau metode baru adalah Cooperative Learning, Role Playing, Study Tour, Group Investigation, Contextual Learning, Cooperative Script, Jigsaw, Gallery Walk, Card Sort, Values Exploration dan Windows Shopping.

\section{DAFTAR PUSTAKA}

Abduhzen, M. (2018). Kompetensi Kepribadian Guru. Harian Kompas, p. 6.

Abedini, S., \& Broujeni, R. B. (2016). Teacher $\{$ Creativity\} in \{University\} $\{$ Students\}' \{Views\}: $\{\mathrm{A}\}$ \{Content \{Analysis\}. International Journal of Pharmaceutical Research \& Allied Sciences, 5(3), 379-386. Retrieved from http://search.ebscohost.com/login.aspx?direct=true\&db=a9h\&AN=120466915\&lan $\mathrm{g}=\mathrm{es} \&$ site $=$ ehost-live

Adair, J. (2007). The Art of Creative Thinking How to be Innovative and Develop Great Ideas. London: Kogan Page Limited.

Constantinides, M. (2015). Eight steps to becoming a more creative teacher. Retrieved from https://www.britishcouncil.org/voices-magazine/eight-steps-becoming-morecreative-teacher

Creswell, John. terjemahan Helly Prayitno Soetjipto, S. M. S. (2015). Riset Pendidikan Prencanaan, Pelaksanaan, dan Evaluasi Riset Kualitatif \& Kuantitatif (Kelima). 264 | Seminar Nasional Sejarah ke 4 Jurusan Pendidikan Sejarah Universitas Negeri Padang 
Yogyakarta.

Daly, S. R., Mosyjowski, E. A., \& Seifert, C. M. (2014). Teaching creativity in engineering courses. Journal of Engineering Education, 103(3), 417-449. https://doi.org/10.1002/jee.20048

Morais, M. F., \& Azevedo, I. (2011). What is a creative teacher and what is a creative pupil? Perceptions of teachers. Procedia - Social and Behavioral Sciences, 12(October 2015), 330-339. https://doi.org/10.1016/j.sbspro.2011.02.042

Morissan. (2016). Metode Penelitian Survei. Jakarta: Kencana.

National Advisory Committee on Creative and Cultural Education All Our Futures : Creativity, Culture and Education. (1999), (May).

Petkovska, V. (2015). Teaching Creatively in ESP. Journal of Education and Practice, 6(17), 172-175.Retrievedfrom http://proxy.library.vcu.edu/login?url=http://search.proquest.com/docview/177322 1316 ?accountid $=14780$

Pope, R. (2005). Creativity: Theory, History, Practice (Taylor \& F). Oxon: Routledge.

Richards, J. C. (2013). Creativity in Language Teaching. Iranian Journal of Language Teaching Research, 1(3), 19-43.

Riduwan. (2002). Skala Pengkuran Variabel-Variabel Penelitian. Bandung: Alfabeta.

Rowe, A. J. terjemahan S. A. (2005). Creative Intelligence Membangkitkan Potensi Inovasi dalam Diri dan Organisasi Anda (Cetakan I). Bandung: Penerbit Kaifa.

Terry, H. (2018). Teacher Creativity and School Climate, 226(Icss), 708-710.

the SCoTENS Committee and Secretariat. (2012). Creative Teachers for Creative Learners Implications for Teacher Education. Dublin.

Wilson, A., \& Cremin, T. (2017). Creative Teachers and Creative Teaching. Creativity in Primary Education, (January 2014), 33-44.https://doi.org/10.4135/9781473909 403.n4 